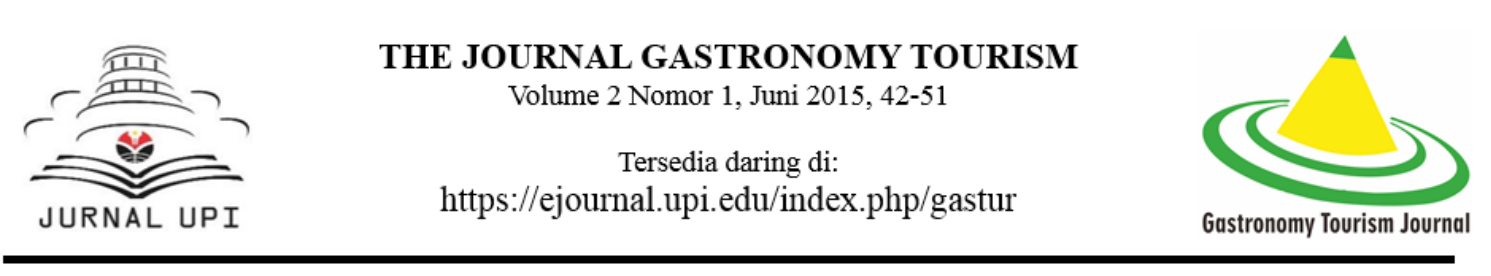

\title{
STRATEGI PENGEMBANGAN USAHA PADA GAMA CATERING DI KOTA BANDUNG
}

\author{
Ega Dharma Yogaswara, Agus Sudono, Sylvia Meilani \\ Program Studi Manajemen Industri Katering \\ Fakultas Pendidikan Ilmu Pengetahuan Sosial \\ Universitas Pendidikan Indonesia \\ ega2207@yahoo.com
}

\begin{abstract}
Food and baverages industrial expansions in Bandung City had increased in every years, based on data from Badan Pusat Statistik Kota Bandung which had increased 5,18\% on second quarter in 2013. This indication increase competition affect concering on food and baverages service, as well as catering service inside. based on data from Asosiasi Pengusaha Jasa Boga Indonesia Kota Bandung (APJI) 127 industry signed as food and baverages service in Bandung City. Gama Catering is one of each catering service industry in Bandung City. To maintain in order to existention consuct bussiness expansion strategy form competition to have get costumer from competitor industry service in food and baverages sector.

This research was using descriptive analysis, to know illustration of it oppotunities, threats, weeknesess, strengths owned by Gama Catering and for business development it used SWOT matrix. Descriptive Quantitaive analysis using EFE, IFE, IE, QPSM matrix. Data proccessing had resulting 16 alternative strategy in developing it business. The priority of alternative strategy with TAS point reachs 6,495 was : Sustable innovation of it's quality service and product in order to create costumer satisfaction and loyality.

Keyword : Catering expensions Industrial, SWOT analysis, and QPSM.
\end{abstract}

\begin{abstract}
ABSTRAK
Perkembangan industri makanan dan minuman di Kota Bandung mengalami peningkatan setiap tahunnya, hal ini didapatkan berdasarkan data yang diberikan oleh Badan Pusat Statistik Kota Bandung yang pada kuartal II di tahun 2013 mencapai kenaikan sebesar 5,18\%. Gejala ini dapat meningkatkan persaingan dalam hal pelayan jasa pada bidang jasa boga, termasuk pelayan katering didalamnya. Berdasarkan data dari Asosiasi Pengusaha Jasa Boga Indonesia kota Bandung (APJI) terdapat 127 perusahaan pelayanan katering yang terdapat di Kota Bandung. Gama Catering adalah salah satu perusahaan pelayanan katering yang ada di Kota Bandung. Oleh karena itu untuk dapat mempertahankan eksistensi dari perusahaan dibutuhkan pengembangan bisnis agar mampu berkompetisi guna menarik konsumen dari para pesaing dibidang pelayanan jasa tata boga ini.

Analisis yang digunakan adalah analisis Deskriptif, hal ini bertujuan untuk dapat mengetahui gambaran mengenai lingkungan perusahaan terkait dengan peluang, ancaman, kekuatan, dan kelemahan yang dimiliki oleh Gama Catering serta
\end{abstract}


perumusan analisi strategi dengan menggunakan Matriks SWOT. Analisis Deskriptif Kuantitatif menggunakan matriks EFE, IFE, IE, dan QSPM. Dari pengolahan data menggunakan metode diatas menghasilkan 16 alternatif strategi untuk pengembangan usaha. Adapun alternatif strategi yang menjadi prioritas utama adalah : Melakukan inovasi berkelanjutan dalam rangka peningkatan kualitas dan pengembangan produk untuk meraih kepuasan dan loyalitas pelanggan dengan nilai TAS sebesar 6,495.

Kata kunci : Pengembangan Usaha Katering, Analisis SWOT, dan QSPM.

\section{PENDAHULUAN}

Kota Bandung merupakan kota metropolitan terbesar di Jawa Barat sekaligus menjadi ibu kota provinsi. Kota Bandung terletak $140 \mathrm{~km}$ dr ibu kota negara Jakarta, dan merupakan kota satelit penopang ibu kota negara dan juga sebagai kota terbesar ketiga di indonesia setelah Ibu Kota Jakarta dan Surabaya dari sisi jumlah penduduk.

Kota kembang merupakan sebutan lain untuk kota ini, karena pada zaman dulu kota ini dinilai sangat cantik dengan banyaknya pohon-pohon dan bunga-bunga yang tumbuh di sana. Selain itu Bandung dahulunya disebut juga dengan Parijs van Java karena keindahannya karena letaknya yang berada di dataran tinggi memberi hawa sejuk seperti layaknya kota Paris. Tetapi pada saat ini julukan kota kembang itu perlahan mulai sirna ditelan perkrmbangan jaman. Dimana pepohonan dan bungabunga yang indah bertebaran di sisi jalan kini sudah berubah menjadi "Pohon Beton" gedung-gedung perkantoran dan gedung perbelanjaan yang sudah memenuhi lahan hijau di Kota Bandung.

Selain memiliki puluhan factory outlet yang tersebar di seluruh penjuru daerah, Kota Bandung juga memiliki potensi bisnis kuliner yang sangat beragam. Dari mulai menu masakan nusantara hingga menu kuliner mancanegara, ditawarkan para pelaku usaha untuk memanjakan para pecinta kuliner di daerah Bandung dan sekitarnya. Melihat banyaknya peluang usaha kreatif yang terdapat di daerah Bandung, tidaklah heran bila Kota Bandung menjadi gudangnya para pebisnis kreatif dan menjadi salah satu daerah di Indonesia yang ikut serta mendukung pertumbuhan ekonomi kreatif di tingkat nasional.

Salah satu bagian dari industri makanan dan minuman adalah industri jasa boga. Dimana di dalamnya terdapat usaha jasa katering. Bisnis jasa katering pada saat ini sangat diminati oleh banyak orang, karena banyaknya permintaan dari masyarakat yang memerlukan jasa tersebut. Karena pada saat ini kebanyakan orang tidak mau ambil pusing apabila mengadakan suatu acara yang membutuhkan pelayanan makanan dan minuman, dari itulah jasa pelayanan katering kini menjadi salah satu kebutuhan masyarakat metropolitan.

Saat ini industri pelayanan katering di kota bandung masih dikuasai oleh katering-katering besar ternama di kota bandung, seperti Destiny Catering, Soewardono Catering, dan lain sebagainya. Ini menunjukkan bahwa daya persaingan di bidang jasa penyedia katering ini sangat ketat dan kuat. Pelayanan yang menuaskan juga menjadi salah satu indikator suatu perusahaan katering untuk bisa bersaing secara sehat. Tapi selain itu banyak juga katering yang mamiliki pelayanan prima dan memberikan citarasa masakan yang terjamin kualitasnya, salah satunya Gama Catering. 
Gama Catering didirikan di kota Bandung yang beralamat di Komp. Bumi Panyileukan Blok F 14 No. 8 sejak tahun 1998. Pada awalnya perusahaan ini hanya melayani pesanan nasi dus dan tumpeng saja dengan karyawan keluarga sendiri, seiring berjalannya waktu kini Gama Catering sudah melayani pesanan katering hingga 4000 porsi setiap harinya dengan memperkerjakan 10 karyawan tetap. Perkembangan usaha Gama Catering dari tahu ke tahun mengalami kenaikan yang cukup signifikan. Tetapi ada kendala-kendala yang bisa menghambat dari operasional perusahaan seperti kenaikan bahan baku dan harga bahan bakar gas yang menjadi barang utama yang harus selalu digunakan.

Dari beberapa fenomena di atas, untuk mengangkat fenomena tersebut dan menelaah lebih jauh untuk menganalisis berbagai faktor eksternal dan internal perusahaan untuk menemukan strategi promosi yang terbaik bagi Gama Catering dan strategi guna mengatasi melonjaknya harga bahan baku untuk mengembangkan usahanya.

\section{TUJUAN PENELITIAN}

Penelitian ini bertujuan untuk mengetahui : (1) Menganalisis faktor eksternal yang dilihat dari kelemahan dan kekuatan Gama Catering, (2) Menganalisis faktor internal yang dilihat dari kelemahan dan kekuatan Gama Catering, (3) Mengkaji alternatif strategi yang sesuai untuk perkembangan bisnis usaha dari Gama Catering.

\section{METODE PENELITIAN}

Analisis yang digunakan adalah analisis deskiptif digunakan untuk mendapatkan gambaran mengenai lingkungan perusahaan terkait dengan peluang,ancaman,kekuatan dan kelemahan yang dimiliki oleh kedai serta perumusan strategi dengan mengunakan matriks SWOT. Analisis deskipsif kuantatif menggunakan matriks EFE, IFE, IF dan QSPM (Quantitative Strategic Planning Matrix)

\section{Metode Pengolahan dan Analisis Data}

1. Input (Input Stage)Tahap input adalah tahapan pengumpulan informasi untuk merumuskan strategi. Pada tahapan ini dilakukan identifikasi terhadap faktor-faktor internal maupun eksternal yang terjadi kekuatan dan kelemahan dalam perusahaan. Dalam penelitian ini, tahap input menggunakan matriks IFE dan EFE.

a. Analisis Lingkungan Internal dan Eksternal

Dalam tahap analisis faktor- faktor internal dan eksternal dilakukan dengan mendata seluruh kekuatan dan kelemahan yang dimiliki oleh pihak perusaahan. Serta mendata peluang dan ancaman yang dihadapi perusahaan. Dalam penyajian dalam matriks, faktor yang bersifat positif (kekuatan dan peluang) ditulis sebelum faktor yang bersifat negatif (kelemahan dan ancaman).

b. Pemberian Bobot Setiap Faktor

Pada analisis internal dan eksternal, penentuan bobot dilakukan dengan mengajukan kuesioner pada pihak manajemen atau ahli strategi dengan menggunakan metode pairwise comparison

c. Pemberian Peringkat (Rating)

Peringkat (rating) menggambarkan seberapa besar efektif strategi perusahaan saat ini dalam merespon faktor strategis yang ada (company-based) 
2. Tahapan Pencocokkan (Matching Stage). Tahap pencocokan adalah tahapan untuk mencocokan kekuatan dan kelemahan internal dengan peluang dan ancaman eksternal. Tahap pencocokan bertujuan untuk mengetahui posisi perusahaan agar dapat menghasilkan alternatif strategi yang layak bukan untuk memilih strategi yang terbaik. Pada tahapan pencocokan alat analisis menggunakan matriks IE dan matriks SWOT.

a. Matriks Internal-Eksternal (IE)

Matriks IE berguna untuk menampilkan posisi organisasi dalam diagram skematis atau disebut juga sebagai matriks portofolio.

b. Analisis Matriks SWOT

Matriks SWOT digunakan untuk merumuskan alternatif strategi bagi pihak perusahaan. Matriks SWOT merupakan alat untuk mencocokan yang bertujuan membantu manajer dalam mengembangkan strategi

3. Tahapan Keputusan. Tahap keputusan merupakan tahapan terakhir dalam formulasi strategi, yaitu dengan menetapkan alternatif strategi dimana perusahaan menetapkan strategi yang baik untuk terlebih dahulu dilaksanakan. Alat untuk menganalisis pada tahapan ini adalah dengan menggunakan QSPM (Quantitative Strategic Planning Matrix) Adapun enam tahapan yang dibutuhkan untuk mengembangkan QSPM adalah sebagai berikut:

a. Membuat daftar peluang dan ancaman eksternal dan kekuatan dan kelemahan internal perusahaan. Informasi ini diperoleh dari matriks IFE dan EFE.

b. Memberikan bobot untuk masing-masing faktor internal dan eksternal yang sama dengan bobot tiap faktor yang ada pada IFE dan EFE.

c. Mengevaluasi matriks pada tahapan ke dua (pencocokan), dan identifikasi alternatif strategi yang harus dipertimbangkan organisasi untuk diimplemantasikan. Kemudian dicatat pada baris atas QSPM.

d. Menentukan nilai daya tarik (attractiveness Scores-AS). Nilai ini mengindikasikan daya tarik relatif dari masing-masing strategi. Nilai daya tarik relatif dari masingmasing strategi. Adapun nilai daya tarik yang diberikan adalah sebagai berikut: 1= tidak menarik, $2=$ agak menarik, $3=$ cukup menarik dan $4=$ sangat menarik.

e. Menghitung total nilai daya tarik (Total Attractiveness Scores-TAS) nilai ini didapatkan berdasarkan hasil dari perkalian bobot (langkah b) dengan nilai daya tarik (langkah d) dalam tiap baris total nilai daya tarik menunjukan daya tarik relatif untuk masing-masing alternatif strategi. Semakin besar nilainya, maka semakin menarik alternatif strategi tersebut.

Menghitung jumlah total TAS pada masing-masing kolom strategi alternatif strategi yang terpilih. Strategi dengan TAS tertinggi adalah strategi yang paling layak untuk diimplementasikan.

\section{HASIL DAN PEMBAHASAN}

Berdasarkan faktor-faktor internal dan eksternal yang telah diuraikan, kemudian disusun Matriks IFE (Internal Factor Evaluation Matrix) dan Matriks EFE (External Factor Evaluation Matrix). Analisis internal bertujuan mengetahui kekuatan (strengths) dan kelemahan (wekanesses) yang dapat mempengaruhi perkembangan perusahaan. Berdasarkan analisa penulis, teridentifikasi ada 8 faktor 
kekuatan dan 9 faktor kelemahan. Penilaian setiap faktor internal menggunakan pembobotan dan pemberian peringkat

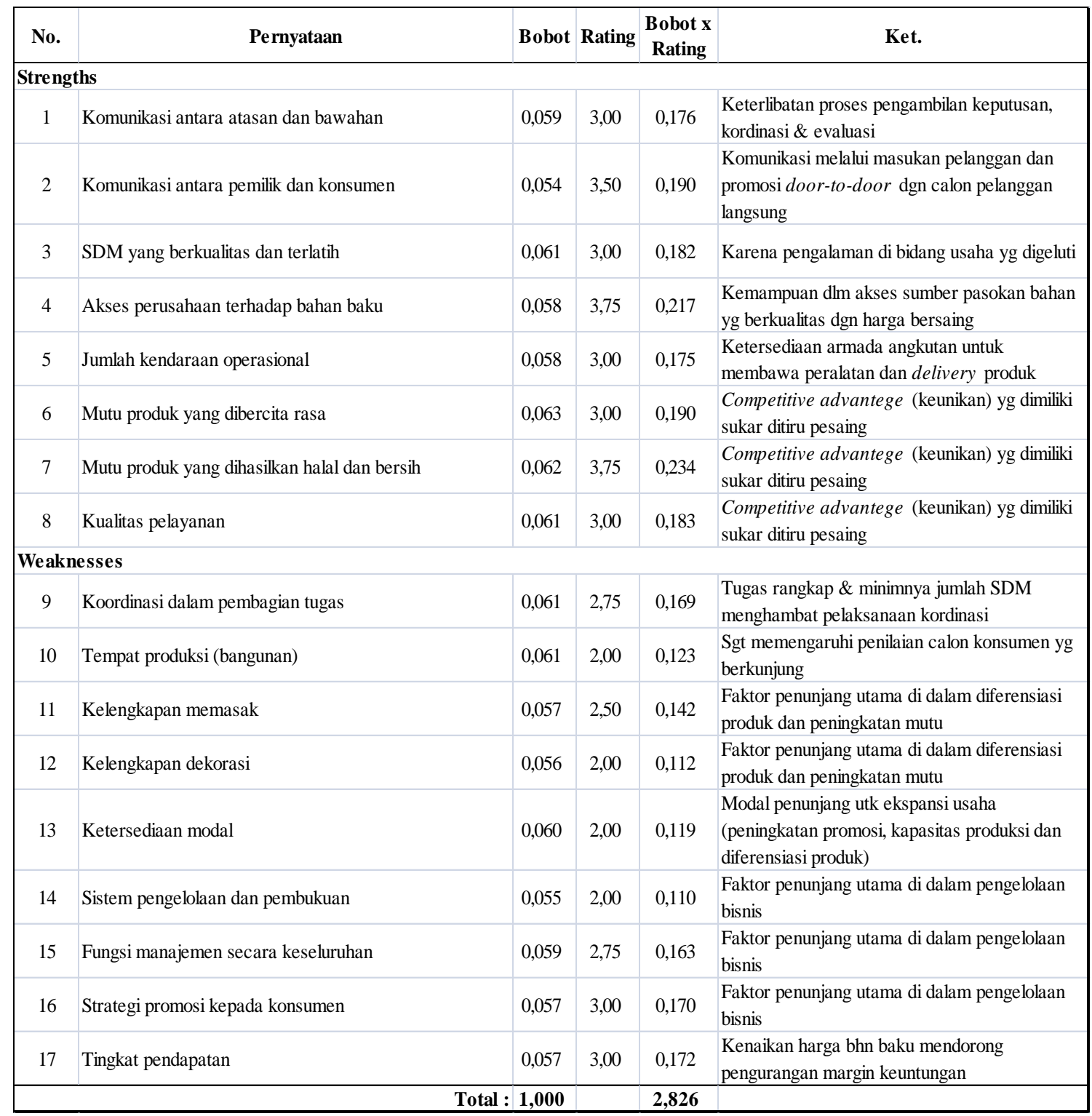

Berdasarkan analisis Matrix IFE dapat diketahui faktor kekuatan bagi Gama Catering adalah mutu produk yang halal dan bersih dengan persentase nilai tertimbang 0,234 poin. Sedangkan faktor kelemahan bagi Gama Catering adalah tingkat pendapatan yang masih kurang stabil tiap periodenya dengan persentase nilai tertimbang 0,172 poin. Dari data diatas dapat disimpulkan bahwa kekuatan utama Gama Catering adalah menyajikan makanan yang halal dan bersih sesuai dengan visi dan misi yang diemban oleh Gama Catering, dan kelemahan utama Gama Catering adalah tingkat pendapatan, ini disebabkan oleh tidak stabilnya harga bahan baku yang mengakibatkan menurunnya margin keuntungan. 
Analisis matriks EFE adalah proses identifikasi factor-faktor eksternal perusahaan dengan tujuan untuk mengetahui peluang (Opportuninies) serta ancaman (Threats) bagi perkembangan perusahaan. Berdasarkan analisa teridentifikasi 8 faktor peluang dan 4 faktor ancaman yang dapat mempengaruhi pengembangan usaha Gama Catering. Matrix EFE adalah mengidentifikasi segala faktor baik di faktor lingkungan ekternal dan internal. Penilaian setiap faktor internal menggunakan pembobotan dan pemberian peringkat.

\begin{tabular}{|c|c|c|c|c|c|}
\hline No. & Pernyataan & Bobot & Rating & $\begin{array}{l}\text { Bobot } x \\
\text { Rating }\end{array}$ & Ket. \\
\hline \multicolumn{6}{|c|}{ Opportunities } \\
\hline 1 & Kebutuhan jasa katering & 0,088 & 3,75 & 0,332 & $\begin{array}{l}\text { Tren budaya praktis yg berkembang di } \\
\text { perkotaan }\end{array}$ \\
\hline 2 & Tingginya permintaan jasa katering & 0,088 & 4,00 & 0,354 & $\begin{array}{l}\text { Tren budaya praktis yg berkembang di } \\
\text { perkotaan }\end{array}$ \\
\hline 3 & Luasnya cakupan pemasaran & 0,092 & 2,50 & 0,231 & $\begin{array}{l}\text { Akses pasar yg luas karena pengalaman di } \\
\text { bidang usaha yg digeluti }\end{array}$ \\
\hline 4 & Pertumbuhan ekonomi di Kota Bandung & 0,065 & 3,00 & 0,196 & $\begin{array}{l}\text { Tren positif thd pertumbuhan ekonomi di Kota } \\
\text { Bandung }\end{array}$ \\
\hline 5 & Daya tawar pemasok (supplier) & 0,085 & 3,00 & 0,254 & $\begin{array}{l}\text { Switching cost pemasok relatif rendah dgn } \\
\text { tersedianya pasar tradisional dan modern }\end{array}$ \\
\hline 6 & Kekuatan tawar menawar harga jasa katering & 0,096 & 3,00 & 0,288 & $\begin{array}{l}\text { Switching cost cukup tinggi shg perusahaan yg } \\
\text { memiliki competitive advantage yg kuat yg } \\
\text { dapat unggul }\end{array}$ \\
\hline 7 & Peningkatan pendapatan dan daya beli masy arakat pada jasa katering & 0,092 & 3,00 & 0,277 & $\begin{array}{l}\text { Indikator peningkatan kesejahteraan masyarakat } \\
\text { Kota Bandung }\end{array}$ \\
\hline 8 & Perkembangan kemajuan teknologi & 0,085 & 3,00 & 0,254 & $\begin{array}{l}\text { Kemajuan internet/komunikasi sebagai media } \\
\text { promosi dan pendukung manajemen }\end{array}$ \\
\hline \multicolumn{6}{|c|}{ Threats } \\
\hline 9 & Kenaikan harga bahan bakar (elpiii) & 0,085 & 3,00 & 0,254 & $\begin{array}{l}\text { Kebijakan konversi dan kenaikan harga bahan } \\
\text { bakar dari pemerintah }\end{array}$ \\
\hline 10 & Kenaikan harga bahan baku & 0,096 & 3,00 & 0,288 & $\begin{array}{l}\text { Inflasi dan tingkat permintaan yg cukup tinggi } \\
\text { mendorong kenaikan harga }\end{array}$ \\
\hline 11 & Banyaknya pesaing di bidang jasa katering & 0,085 & 4,00 & 0,338 & $\begin{array}{l}\text { Entry barrier utk masuk ke industri ini cukup } \\
\text { rendah }\end{array}$ \\
\hline 12 & Tingginya inflasi & 0,042 & 2,00 & 0,085 & Kondisi perekonomian makro \\
\hline \multicolumn{4}{|c|}{ Total : 1,000} & 3,151 & \\
\hline
\end{tabular}

Berdasarkan hasil penghitungan analisis Matrix EFE dapat dilihat faktor peluang dari Gama Catering adalah tingginya permintaan jasa katering dengan persentase nilai tertimbang 0,354 poin. Sedangkan faktor ancaman bagi Gama Catering adalah banyaknya pesaing di bidang jasa katering dengan persentase nilai tertimbang 0,338 poin. Dari data tersebut dapat disimpulkan bahwa peluang bagi Gama Catering sangat terbuka leba, karena didorong dengan trend budaya praktis 
masyarakat perkotaan saat ini. Dan pada hal ancaman juga bisa disimpulkan bahwa semakin meningkatnya permintaan jasa katering mengakibatkan tingginya persaingan di bidang jasa kuliner ini dengan semakin banyaknya penyedia jasa katering yang semakin menjamur di kota Bandung.

\begin{tabular}{|c|c|c|c|}
\hline Pe ringkat & \begin{tabular}{|c|} 
Alte rnatif s trate gi \\
\end{tabular} & Strategi & Skor \\
\hline 1 & $\begin{array}{l}\text { Membangun relasi dengan pihak perbankan dan } \\
\text { pemerintah di dalam memperoleh kemudahan akses } \\
\text { peningkatan pemodalan usaha }\end{array}$ & $\mathrm{W}-\mathrm{O}$ & 0,814 \\
\hline 2 & $\begin{array}{l}\text { Meningkatkan kapasitas produksi yang disertai dengan } \\
\text { keunggulan kualitas pelayanan }\end{array}$ & $\mathrm{S}-\mathrm{O}$ & 0,787 \\
\hline 3 & $\begin{array}{l}\text { Meningkatkan promosi usaha dan memperluas kerja } \\
\text { sama bisnis dalam rangka memperluas distribusi dan } \\
\text { peningkatan penjualan }\end{array}$ & $\mathrm{S}-\mathrm{O}$ & 0,756 \\
\hline 4 & $\begin{array}{l}\text { Menciptakan budaya perusahaan yg kondusif dlm } \\
\text { menciptakan lingkungan kerja yang nyaman dan terbuka } \\
\text { terhadap usulan (ide) baru }\end{array}$ & $\mathrm{W}-\mathrm{O}$ & 0,636 \\
\hline 5 & $\begin{array}{l}\text { Melakukan pemberdayaan karyawan sebagai marketing } \\
\text { public relation dalam upaya terus menjalin hubungan yang } \\
\text { baik dengan pelanggan }\end{array}$ & $\mathrm{W}-\mathrm{O}$ & 0,592 \\
\hline 6 & $\begin{array}{l}\text { Menciptakan struktur organisasi yang efektif dan efisien } \\
\text { sehingga memudahkan pengontrolan kualitas dan } \\
\text { mengantisipasi kendala }\end{array}$ & $\mathrm{W}-\mathrm{T}$ & 0,541 \\
\hline 7 & Melakukan efisiensi biaya produksi dan distribusi & W-T & 0,539 \\
\hline 8 & $\begin{array}{l}\text { Pengembangan kapasitas SDM organisasi untuk } \\
\text { mewujudkan total quality services }\end{array}$ & $\mathrm{W}-\mathrm{O}$ & 0,534 \\
\hline 9 & $\begin{array}{l}\text { Meningkatkan intensitas koordinasi dengan relasi bisnis \& } \\
\text { konsumen dalam rangka mengatasi solusi dan kendala } \\
\text { bisnis }\end{array}$ & S-T & 0,480 \\
\hline 10 & $\begin{array}{l}\text { Mengimplementasikan sistem pengarsipan dan database } \\
\text { bisnis sebagai dasar pertimbangan pengambilan } \\
\text { keputusan }\end{array}$ & W-T & 0,479 \\
\hline 11 & $\begin{array}{l}\text { Menerapkan SOP \& QC system yang ketat dan berkala } \\
\text { dalam proses produksi dan distribusi }\end{array}$ & W-T & 0,428 \\
\hline 12 & $\begin{array}{l}\text { Melakukan inovasi berkelanjutan dalam rangka } \\
\text { peningkatan kualitas dan pengembangan produk untuk } \\
\text { meraih kepuasan dan loyalitas pelanggan }\end{array}$ & S-T & 0,368 \\
\hline 13 & $\begin{array}{l}\text { Menjalin komunikasi dan negosiasi bisnis yang saling } \\
\text { menguntungkan dengan para suplier dalam hal strategi } \\
\text { pengamanan kualitas dan kuantitas pasokan produk }\end{array}$ & S-T & 0,322 \\
\hline 14 & $\begin{array}{l}\text { Secara berkala melakukan evaluasi, seleksi dan } \\
\text { pengembangan kemitraan dengan pemasok lama maupun } \\
\text { baru }\end{array}$ & $\mathrm{W}-\mathrm{O}$ & 0,282 \\
\hline 15 & $\begin{array}{l}\text { Menciptakan mekanisme transfer pengetahuan dan } \\
\text { teknik kinerja yang unggul di dalam struktur bisnis }\end{array}$ & $\mathrm{S}-\mathrm{O}$ & 0,258 \\
\hline 16 & $\begin{array}{l}\text { Pemanfaatan kemajuan teknologi untuk meningkatkan } \\
\text { mutu dan pelayanan terhadap pelanggan }\end{array}$ & $\mathrm{S}-\mathrm{O}$ & 0,198 \\
\hline
\end{tabular}

Analisis matriks IE adalah penggambungan antara hasil analisis dari matriks IFE (Internal Factor Evaluation) dan EFE (Eksternal Factor Evaluation). Hasil dari analisis matriks IFE terhadap faktor kunci eksternal menghasilkan total nilai tertimbang sebesar 2,826. Hal ini mengidentifikasikan bahwa perusahaan dapat memanfaatkan kekuatan dan mengatasi kelemahan perusahaan dengan baik. 
Sedangkan hasil dari analisis matriks EFE terhadap faktor kunci eksternal menghasilkan total nilai tertimbang sebesar 3,151. Hal ini mengidentifikasikan bahwa perusahaan dapat memanfaatkan peluang serta mengatasi ancaman dengan baik. Hasil total nilai tertimbang dari analisis matriks IFE dan matriks EFE kemudian dipetakan dalam matriks IE (Internal-Eksternal). Berdasarkan hasil analisis Matrix IE dapat diketahui bahwa Gama Catering berada pada posisi kuadran II. Kuadran II dapat digambarkan sebagai tumbuh dan membangun (grow and build). Ini menunjukkan posisi Gama Catering pada strategi intensif (Penetrasi pasar, pengembangan pasar, dan pengembangan produk) atau dapat disebut juga strategi integrasi. Strategi intensif penetrasi pasar dapat diartikan sebagai strategi untuk meningkatkan pangsa pasar untuk produk yang ada di pasar melalui peningkatan usaha.

Analisis matriks SWOT adalah alat yang digunakan untuk mencocokan antara sumber daya dan keterampilan internal dengan peluang dan ancaman yang diciptakan oleh faktor internal. Analisis matriks SWOT menggunakan hasil indentifikasi analisis yang bersumber dari matriks IFE dan EFE. Matriks IFE mengidentikasi faktor-faktor internal perusahaan berupa kekuatan dan kelemahan sedangkan matriks EFE mengidentifikasikan peluang serta ancaman dari luar perusahaan yang dapat berakibat pada faktor internal.

Analisis QSPM adalah analinis yang bertujuan untuk menentukan prioritas pelaksaan strategi dengan menentukan daya tarik relatif (attractiveness Score-AS) dari alternatif tindakan yang layak. Teknk ini mengindikasikan alternatif strategi mana yang terbaik yang dilakukan oleh perusahaan. Pemilihan strategi QSPM dilakukan oleh pihak Gama Catering sebagai pengambil kebijakan perusahaan. Alternatif strategi yang telah dihasilkan diperingkatkan dengan jumlah total nilai daya tarik atau Sum Total Attractiveness Score (STAS). Semakin tinggi STAS, menunjukkan bahwa strategi tersebut menarik dengan mempertimbangkan semua faktor sukses kunci internal dan eksternal relevan yang dapat mempengaruhi keputusan strategi. Berdasarkan hasil analisis QSPM diatas, dapat diketahui prioritas dari alternatif strategi. Adapun prioritas utama dari alternatif strategi bagi Gama Catering adalah "Melakukan inovasi berkelanjutan dalam rangka peningkatan kualitas dan pengembangan produk untuk meraih kepuasan dan loyalitas pelanggan (Nilai STAS : 6,495)”.

\section{SIMPULAN}

Berdasarkan hasil penelitian yang telah dilakukan penulis, maka dapat disimpulkan berdasarkan rumusan masalah yaitu sebagai berikut:

1. Hasil analisis lingkungan internal perusahaan menunjukkan bahwa Gama Catering memiliki beberapa faktor kekuatan dan kelemahan yang berkaitan dengan pengembangan usaha dari Gama Catering. Adapun faktor kekuatan yang paling utama bagi Gama Catering adalah "Mutu produk yang dihasilkan halal dan bersih ". Ini karena competitive advantage (keunikan)yang dimiliki sulit untuk ditiru oleh pesaing dan menggunakan yang terjaga kualitas dan kebersihannya 
Adapun faktor kelemahan utama yang menjadi kendala bagi Gama Catering adalah "Tingkat pendapatan". Ini dikarenakan kenaikan harga bahan baku sehingga mendorong pengurangan margin keuntungan.

2. Hasil analisis lingkungan eksternal perusahaan menunjukkan bahwa Gama Catering memiliki beberapa faktor peluang dan ancaman yang berkaitan dengan pengembangan usaha dari Gama Catering. Adapun faktor peluang yang menjadi prioritas utama adalah "Tingginya permintaan jasa katering". Ini didorong dengan adanya trend budaya praktis masyarakat perkotaan saat ini.

Sedangkan faktor ancaman yang sangat mempengaruhi bagi Gama Catering adalah "Banyaknya pesaing di bidang jasa katering". Semakin meningkatnya permintaan jasa katering mengakibatkan tingginya persaingan di bidang jasa kuliner khusussnya jasa katering.

3. Setelah dianalisis melalui matriks EFE, IFE, IE, dan QSPM menghasilkan beberapa alternatif strategi untuk mengembangkan usaha bagi Gama Catering kedepannya. Adapun alternatif utama yang menjadi prioritas menurut hasil pengolahan data QSPM adalah "Melakukan inovasi berkelanjutan dalam rangka peningkatan kualitas dan pengembangan produk untuk meraih kepuasan dan loyalitas pelanggan".

Berdasarkan kesimpulan di atas, maka saran yang dapat dikemukakan adalah untuk meningkatkan strategi pengembangan usaha pada Gama Catering adalah :

1. Gama Catering harus mempertahankan hubungan yang baik dengan karyawan agar tercipta suasana nyaman dalam lingkungan pekerjaan dan kondusif.

2. Gama Catering harus mempertahankan hubungan yang baik dengan para pelanggan.

3. Gama Catering harus menjaga dan mempertahankan mutu, rasa, dan pelayanan katering.

4. Menambah dan melengkapi peralatan dekorasi.

5. Memperluas dan memperbesar dapur.

6. Menawarkan kerjasama kepada investor

7. Gama Catering harus memanfaatkan dan memaksimalkan teknologi guna mempromosikan usahanya.

8. Mencari alternatif pemasok bahan baku lokal untuk mengatasi hambatan pasokan bahan baku.

9. Memperluas cakupan pemasaran agar volume penjualan meningkat.

\section{DAFTAR PUSTAKA}

Atmodjo, Marsum Widjojo.(2007).Restoran dan segala Permasalahannya.

Yogyakarta: Andi

Bagyono (2005).Pariwisata dan Perhotelan.Bandung:Alfabeta

Buchari, Alma (2004). Manajemen Pemasaran dan Pemasaran Jasa. Bandung:Alfabeta

David, Fred R.(2009). Jakarta. Manajemen Strategis Konsep,Terjemahan, Jakarta:Penerbit Salemba Empat.

Dirgantoro, Corwn (2004).Manajemen Strategis Konsep, Kasus dan Implementasi,Terjemahan.Jakarta:PT.Grasindo. 
Rachmat. (2009). "Analisis Strategi pengembangan Usaha Jasa Boga Kesehatan Pada Prima Diet Catering, Jakarta ".Skripsi Pada Program Studi Manajemen Agribisnis Fakultas Pertanian IPB: Tidak diterbitkan

Geryansyah, Dona.(2011). "Unsur-unsur Perencanaan Dalam Penyelenggaraan

Hunger, J.D dan Wheelen, T.L.(2005). Manajemen Strategis. Terjemahan. Edisi kedua. Yogyakarta: Andi

Rangkuti, Freddy. (2009).Analisis SWOT Teknik Membedah Kasus Bisnis Reorientasi Konsep Perencanaan Strategis Untuk Menghadapi Abad 21,Jakarta:PT.Gramedia Pustaka Utama.

Suwarsono, Muhammad (2002) Manajemen Strategik Konsep dan Kasus. Yogyakarta:UPP AMP YKPN.

Kotler, Philip.(2007). Manajemen Pemasaran, Terjemahan. Jilid 1.Jakarta;PT.Indeks Kotler, Philip.(2009). Manajemen Pemasaran, Terjemahan. Jilid 2.Jakarta;PT.Indeks

Laporan Keterangan Pertanggung Jawaban Walikota Bandung (2011), Bandung: Pemerintah Kota Bandung.

PB, Triton.(2007). Manajemen Strategis: Terapan Perusahaan dan Bisnis. Yogyakarta; Tugu Publisher.

Siahaan PE. 2008. Analisis Strategi Pengembangan Usaha Restoran Rice Bowl Skripsi Pada Program Studi Manajemen Agribisnis Fakultas Pertanian IPB: Tidak diterbitkan

Sugiarto, Endar dan Sri Sulatirningrum. (2000). Pengantar Akomodasi dan Restoran. Jakarta PT. Gramedia Pustaka

Sugiyono.(2011). Statiska untuk Penelitian. Bandung; CV.Alfabeta

Sumber Lainnya :

id.m.wikipedia.org/wiki/Kota_Bandung [12 Juni 2014]

kateringmalang.wordpress.com/2010/11/20/definisi-katering 